\title{
The mitochondrial permeability transition pore and cancer: molecular mechanisms involved in cell death
}

\section{Massimo Bonora and Paolo Pinton*}

Section of Pathology, Oncology and Experimental Biology, Laboratory for Technologies of Advanced Therapies (LTTA), Department of Morphology, Surgery and Experimental Medicine, University of Ferrara, Ferrara, Italy

\section{Edited by:}

Hans-Uwe Simon, University of Bern, Switzerland

Reviewed by:

Gavin P. McStay, New York Institute of Technology, USA

Paulo J. Oliveira, Center for

Neuroscience and Cell Biology,

Portugal

\section{${ }^{*}$ Correspondence:}

Paolo Pinton, Section of Pathology, Oncology and Experimental Biology,

Laboratory for Technologies of

Advanced Therapies (LTTA),

Department of Morphology, Surgery and Experimental Medicine,

University of Ferrara, Via Fossato di

Mortara 70 (c/o CUBO), Ferrara

44121, Italy

e-mail:pnp@unife.it
Since its discovery in the 1970s, the mitochondrial permeability transition (MPT) has been proposed to be a strategic regulator of cell death. Intense research efforts have focused on elucidating the molecular components of the MPT because this knowledge may help to better understand and treat various pathologies ranging from neurodegenerative and cardiac diseases to cancer. In the case of cancer, several studies have revealed alterations in the activity of the mitochondrial permeability transition pore (mPTP) and have determined its regulatory mechanism; these studies have also suggested that suppression of the activity of the MPTP, rather than its inactivation, commonly occurs in solid neoplasms. This review focuses on the most recent advances in understanding MPTP regulation in cancer and highlights the ability of the MPTP to impede the mechanisms of cell death.

Keywords: apoptosis, cancer, necrosis, permeability transition pore, ATP synthase, ROS, tumors, PTP

\section{INTRODUCTION}

The mitochondrial permeability transition (MPT) refers to an alteration in the permeability of the inner mitochondrial membrane (IMM), which was characterized for the first time in 1979 (1). The interest in this unusual mitochondrial state increased exponentially in the 1990s after the MPT was shown to be a strategic regulator of cell death (2). In the earliest study on this subject, the MPT was shown to be induced by high concentrations of mitochondrial $\mathrm{Ca}^{2+}\left(\left[\mathrm{Ca}^{2+}\right]_{\mathrm{m}}\right)$ and to be inhibited by $\mathrm{Mg}^{2+}$ and adenosine diphosphate (ADP) (1). In a later study, oxidative stress was also reported to induce the MPT (3). Thus, $\left[\mathrm{Ca}^{2+}\right]_{\mathrm{m}}$ and oxidative stress are currently known as the two stereotypical activators of MPT. The MPT has detrimental effects not only on

Abbreviations: ANT, adenine nucleotide translocator; $\mathrm{Bax}, \mathrm{Bcl}-2$-associated protein $\mathrm{X}$; Bak, Bcl-2 homologous antagonist killer; Bcl-2, B-cell lymphoma 2; Bcl-Xl, B-cell lymphoma-extra large; CypD, cyclophilin D; CK, creatine kinase; CsA, cyclosporine A; ER, endoplasmic reticulum; GSK3 $\beta$, glycogen synthase kinase 3 beta; HIF $1 \alpha$, hypoxia-inducible factor 1 alpha; HKII, hexokinase 2; H-RAS, Harvey rat sarcoma viral oncogene homolog; HSP60, heat shock protein 60; HSP90, heat shock protein 90; IMM, inner mitochondrial membrane; IP3R, inositol phosphate 3 receptor; MAMs, mitochondria-associated membranes; Mcl-1, myeloid cell leukemia 1; MPT, mitochondria permeability transition; $\mathrm{mPTP}$, mitochondrial permeability transition pore; OMM, outer mitochondrial membrane; $\mathrm{PKC}$, protein kinase C; $\mathrm{PML}$, promyelocytic leukemia; PP2A, protein phosphatase 2A; PTEN, phosphatase and tensin homolog; ROS, reactive oxygen species; SOD-2, superoxide dismutase-2; TRAP-1, TNF receptor-associated protein-1; TRX-2, thioredoxin reductase; TSPO, translocator protein; VDAC, voltage-dependent anion channel; WNT, wingless-type MMTV integration site family member. mitochondria but also on the entire cell. A loss of IMM permeability leads to rapid loss of the mitochondrial membrane potential $(\Delta \Psi \mathrm{mt})$ and the consequent loss of adenosine triphosphate (ATP) as well as osmotic shock to the organelle and rupture of the outer mitochondrial membrane (OMM). The loss of ATP causes a loss of ion homeostasis and cell integrity, which finally results in necrosis (4).

Interestingly, these acute phenomena are efficiently prevented by the immunosuppressive cyclosporine A (CsA) $(5,6)$, indicating that the pharmacological target of CsA, the mitochondrial peptidyl-prolyl isomerase $\mathrm{F}$ [also known as cyclophilin $\mathrm{D}(\mathrm{CypD})$ ], may play an important role in the MPT $(7,8)$ (see below).

It would be insufficient and inaccurate to assume that the MPT only results in necrotic cell death. The rupture of the OMM that occurs during mitochondrial swelling can lead to the release of mitochondrial proapoptotic factors, such as cytochrome C (9), apoptosis-inducing factor (AIF) (10), second mitochondriaderived activator of caspases (SMAC)/direct IAP-binding protein with low PI (DIABLO) (11), and endonuclease G (EndoG) (12), and each of these factors can induce proapoptotic activity in different ways. A role for the MPT in apoptotic cell death has been supported by several studies. For example, isolated mitochondria exposed to MPT-inducing stimuli undergo apoptotic-like morphological rearrangements when mixed with isolated nuclei (13). The MPT inhibitor bongkrekic acid (14) inhibits cell death, while the MPT inducer atractyloside (9) renders the cell more susceptible to cell death. Additionally, the proapoptotic protein B-cell lymphoma (BCL)-associated X 
(Bax) can induce loss of the $\Delta \Psi \mathrm{mt}$ in a CsA-sensitive manner $(15,16)$.

Considering that ATP is a critical component in apoptosis, it is possible that the loss of mitochondrial ATP synthesis (17) as a result of the MPT would not allow MPT-driven apoptosis. This possibility is partially supported by studies showing that loss of the $\Delta \Psi \mathrm{mt}$ does not occur with certain apoptotic stimuli [however, loss of the $\Delta \Psi \mathrm{mt}$ is not necessarily due to an opening of the mitochondrial permeability transition pore (mPTP), and mPTP activity data based on $\Delta \Psi \mathrm{mt}$ measurements must always be validated by other assays using CsA or other mPTP inhibitors]. Based on these findings, the MPT may not involve the entire mitochondrial network within the cell, and the MPT may only occur at the level of individual mitochondria (18). These isolated events could generate a localized and multi-phasic release of mitochondrial proapoptotic factors that would eventually result in apoptosis $(19,20)$. The cytoplasm, but not the mitochondria, may be the source of ATP during apoptosis. In this case, an apoptotic event induced by the MPT could proceed even when loss of the $\Delta \Psi \mathrm{mt}$ occurs (21).

Additional information about the involvement of the MPTP in apoptotic and necrotic cell death arrive from two different studies on transgenic mice lacking the ppif gene, which encodes mitochondrial CypD (22). Both studies clearly indicate a strategic role for CypD in MPT-induced necrosis, as cells from ppif-/mice appear to be resistant to necrosis induced by both $\mathrm{Ca}^{2+}$ and oxidative stress, as measured by several readouts. The relationship between the mPTP and apoptosis is less clear. Both papers clearly show that exposure of isolated mitochondria to $\mathrm{Ca}^{2+}$ induces cytochrome $\mathrm{C}$ release from ppif $+/+$ cells, while the same does not occur in ppif-/-cells because this release is considered one of the master events in the mitochondrial pathway of apoptosis, which suggests that the MPTP maintains a role in regulating apoptosis induction (22). Unfortunately, both papers also show no differences in apoptosis induction between the two different backgrounds (wt and ko) when induced by stimuli such as staurosporine and TNF alpha or during tBid and Bax overexpression.

The observation of a CypD-dependent cytochrome $\mathrm{C}$ release triggered by $\mathrm{Ca}^{2+}$ in a system that does not display CypDdependent apoptosis is paradoxical. The first possible interpretation of the paradox is that MPTP opening is able to induce cytochrome $\mathrm{C}$ release, but the alteration of cellular homeostasis is so rapid and dramatic that necrosis overcomes apoptosis. Another possible explanation involves the dose and timing of the stimuli. For example, in the study of Nakagawa, $\mathrm{H}_{2} \mathrm{O}_{2}$ was used as a stimulus to induce cell death. In this case, the cells answered by engaging necrosis but not apoptosis; however, it has been extensively reported that hydrogen peroxide treatment is also able to induce apoptosis [for instance, see in Ref. (23-26)]. Finally, it should be considered that CypD is not a structural component of $\mathrm{MPTP}$, but is one of its regulators (maybe the most investigated of all), and its role in the complex is to regulate the threshold for $\mathrm{Ca}^{2+}$; however, mPTP opening is still achievable. Because the mPTP opening mechanism in response to stimuli such as Bax and Bid is unclear, these proteins may not require $\mathrm{Ca}^{2+}$ to trigger the MPT and thus would not require CypD.

Overall, studies on ppif ko mice clearly show that $\mathrm{Ca}^{2+}$ is a trigger for MPT-induced necrosis, but these studies do not exclude the possibility that MPT is an apoptotic inducer that responds to other types of triggers.

In conclusion, although the specific type of cell death caused by the MPT has not been confirmed, the mere existence of the MPT indicates that mitochondria are master regulators of danger signals and are capable of transducing life or death signals due to their interconnection with $\mathrm{Ca}^{2+}$ signaling (27-31).

\section{BACKGROUND ON MPTP STRUCTURE}

The MPTP is the putative pore responsible for the MPT, an event in which the mitochondrial inner membrane, which is highly impermeable, becomes extremely permeable. The initial model of the MPTP proposed that the voltage-dependent anion channel (VDAC) and the adenosine nucleotide transporter (ANT) were located on the OMM and IMM, respectively and that they were core components of the pore. These proteins are surrounded by a series of regulators, including kinases such as hexokinase II (HKII), creatine kinase $(\mathrm{CK})$, and glycogen synthase kinase $3 \beta$ (GSK3 $\beta$ ) (32); the translocator protein (TSPO); CypD; and members of the Bcl-2 family $(22,33)$. In particular, the proapoptotic members Bax and Bcl-2 homologous antagonist killer (Bak) have a dramatic positive effect on mPTP opening, as confirmed in bax and bak knockout models (34). The role of these proteins in the regulation of MPT is likely to depend on their ability to permeate the OMM, which was partially confirmed in an older study illustrating that the removal of Bax and Bak led to impaired mitochondrial $\mathrm{Ca}^{2+}$ uptake (35).

The results from VDAC and ANT knockout studies in animal models, however, have demonstrated that these elements are not pore-forming components; thus, they have been categorized in the broad group of activity regulators.

The observation that inorganic phosphate sensitizes the MPTP suggests that a Pi-binding protein could be associated with the pore. For a long time, it was thought that this component was an inorganic phosphate transporter $(\mathrm{PiC})$ based on the observations that: (i) a non-specific pore is generated in liposomes by reconstituting the $\mathrm{PiC}$ (36), (ii) the $\mathrm{PiC}$ interacts with mitochondrial CypD and ANT (37), (iii) this interaction is strengthened by MPT-inducing agents, whereas MPT-blocking compounds diminish the interaction, and (iv) $\mathrm{PiC}$ overexpression induces mitochondrial dysfunction and apoptosis (38). These results identified $\mathrm{PiC}$ as a strong candidate for the core-forming element of the mPTP.

Recent knockdown/knockout experiments performed both in vitro $(39)$ and in vivo $(40,41)$ have verified that $\mathrm{PiC}$ cannot be the core component; rather, it serves as an additional regulator.

The sensitivity of the mPTP to inorganic phosphate also drew our attention to respiratory complex I, NADH:ubiquinone oxidoreductase (hereafter referred to as Complex I). It has been observed that the Complex I inhibitor rotenone is also an inhibitor of the MPTP, and its effect is dependent on the Pi level (42). Inhibition of the mPTP by rotenone is apparently linked to the 
activity of Complex I rather than to the production of reactive oxygen species (ROS) or depletion of pyridine nucleotides (43). Further, the relationship between Complex I activity and mPTP inhibition appears to be correlated with structural rearrangements of Complex I (44). This finding led Fontaine's group to propose that respiratory Complex I could act as a negative regulator of $\mathrm{mPTP}$ via a direct interaction, which would depend on the activity of Complex I and the availability of substrates (42).

Overall, these findings have provided several hypotheses regarding the regulation of the $\mathrm{MPTP}$; however, a feasible structural model of the mPTP is still lacking.

The results from a series of studies suggest that mitochondrial $\mathrm{F}_{1} / \mathrm{F}_{\mathrm{O}}$ ATP synthase (hereafter referred to as ATP synthase) may be an important component of the mPTP (45-49). Our group was among the first to demonstrate that the $\mathrm{C}$ subunit of mitochondrial ATPase is a fundamental regulator of mPTP activity (50, 51). Inhibiting $C$ subunit expression completely blocks the induction of the MPT by $\mathrm{Ca}^{2+}$ and oxidants, and overexpressing the $\mathrm{C}$ subunit dramatically promotes MPT induction.

Initially, we speculated that the C-ring forms the core of the mPTP. This speculation was supported by a subsequent study demonstrating that currents generated by isolated $\mathrm{C}$ subunits on artificial bilayers and in isolated mitochondria are sensitive to mPTP regulators (52). Despite these findings, no studies have yet shown that C-rings can exist outside of ATP synthase in vivo or that they can form "free C-rings" that are capable of generating currents.

Finally, a recent study by Alavian et al. (53) demonstrated how the C-ring can generate a non-specific current attributable to the mPTP. Specifically, these authors found that isolated $\mathrm{F}_{1} / \mathrm{F}_{\mathrm{O}}$ ATP synthase monomers reconstituted on vesicles can generate currents when bound to CypD and exposed to $\mathrm{Ca}^{2+}$. Additionally, sub-mitochondrial vesicles enriched in ATP synthase can also generate a current that is sensitive to $\mathrm{Ca}^{2+}$ and CsA, and removing the $\mathrm{F}_{1}$ subunit can abolish this sensitivity. Furthermore, $\mathrm{Ca}^{2+}$-induced mitochondrial swelling can cause the $\mathrm{F}_{1}$ subunit to partially detach from the $\mathrm{F}_{\mathrm{O}}$ subunit, and CsA can reverse this partial detachment. Finally, Alavian et al. further speculated that the C-ring rearranges during the induction of the MPT such that its diameter is increased, forming a non-specific channel (Figure 1).

These findings emphasize the role that ATP synthase, and especially its C-ring, plays in $\mathrm{MPTP}$ formation but do not provide a clear structural model for the mPTP. First, the precise conformational rearrangements that promote the generation of a non-specific current must be determined. Until now, only a rearrangement of the C-ring, with the potential involvement of the $\beta$ subunit, has been proposed. Second, the mechanism underlying this conformational change in ATP synthase must be elucidated, and any other subunits that play a role in this rearrangement must be identified. Finally, the roles played by known components of the MPTP must be determined. For example, the mechanism by which targeting of the mPTP regulators affects the sensitivity of pore opening remains unknown.

Although more studies are required, our understanding of the mPTP has improved since it was first identified.

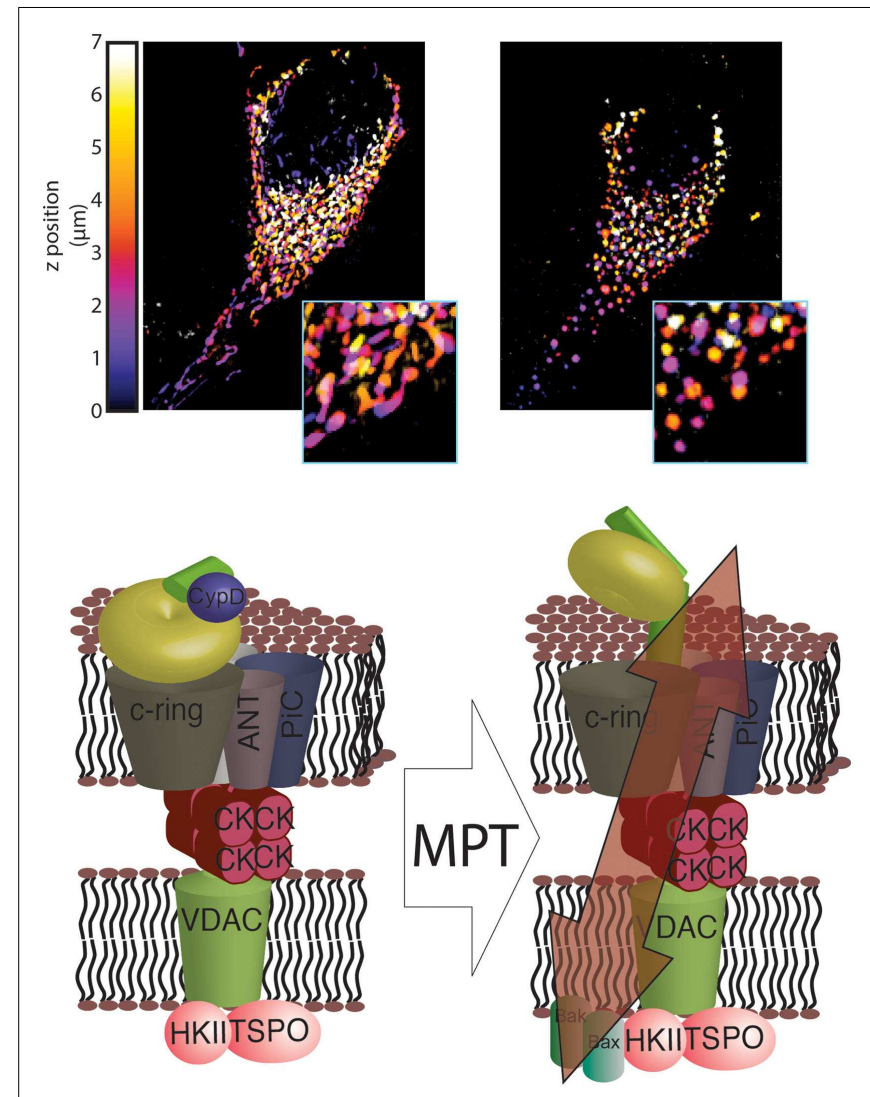

FIGURE 1 | Novel structure of the MPTP. In healthy mitochondria, which are characterized by a dense and interconnected network (top left), the $F_{1} / F_{0}$ ATP synthase is organized into super-structures with the known $\mathrm{mPTP}$ regulators ANT and $\mathrm{PiC}$. These regulators, in turn, are able to interact with other $\mathrm{MPTP}$ regulators, including HKII, VDAC, TSPO and CK (bottom left). Induction of MPT results in a reorganization of the $F_{1} / F_{0}$ ATP synthase structure that allows its $\mathrm{C}$-ring to generate a non-specific current, which leads to mitochondrial network fragmentation and generation of circular mitochondria (mitochondrial swelling, top right). These events, which are usually associated with HKII detachment from the outer mitochondrial membrane (OMM), are facilitated by interaction with GSK3 and by insertion of Bax and Bak into the OMM (bottom right).

\section{MOLECULAR ASPECTS OF THE IPTP IN TUMOR DEVELOPMENT}

Evasion of apoptosis is recognized as one of the hallmarks of cancer and is required for the development and progression of the pathology (54). The mPTP can initiate cell death; thus, it may play a role in cancer.

When considering the potential role of the MPTP in cancer, investigators often question whether changes in MPTP activity promote tumor initiation and progression. Several studies on the mPTP have been conducted in cancer cell lines derived from cervical cancer (50), colon cancer, osteosarcomas (55), leukemia (56), and many other cancers, and these studies have shown that loss of the mPTP itself is not sufficient for cancer development. Despite this observation, several inducers, and other mPTP regulatory events are inefficient in tumor cells. We will discuss a few of these cases in this section. 


\section{ALTERATIONS IN MPT INDUCERS}

The best-known MPT inducer is intra-mitochondrial calcium. Stimuli that elevate the mitochondrial $\mathrm{Ca}^{2+}$ concentration for a sustained period of time induce the MPT and cell death (57, 58). $\mathrm{Ca}^{2+}$ is provided to mitochondria by the endoplasmic reticulum through specialized domains in which the two organelles make contact via mitochondria-associated membranes (MAMs) $(27,28,59)$.

Our group and others have demonstrated that cancer cells evade this type of signaling via several mechanisms. The oncosuppressors promyelocytic leukemia protein (PML) (60) and phosphatase and tensin homolog (PTEN) (61), in cooperation with protein phosphatase $2 \mathrm{~A}$ ( $\mathrm{PP} 2 \mathrm{~A})$, sustain the $\mathrm{Ca}^{2+}$ transfer between the ER and mitochondria through the mitochondrial $\mathrm{Ca}^{2+}$ uniporter (MCU) complex (62) by regulating the phosphorylation state of the channel responsible for the $\mathrm{Ca}^{2+}$ release: the inositol 3 phosphate receptor (IP3R) $(63,64)$. Loss of these regulators inevitably reduces the probability of properly initiating the MPT (31). In contrast, $\mathrm{Bcl}-2$ reduces the $\mathrm{Ca}^{2+}$ content in the ER (65), and the mitogenic kinase AKT strongly inhibits the IP3R; both of these factors favor the inhibition of cytotoxic $\mathrm{Ca}^{2+}$ signals (Figure 2).

It appears that tumor progression is sustained by the accumulation of a series of changes in the $\mathrm{Ca}^{2+}$ regulatory machinery that decrease the cytotoxic $\mathrm{Ca}^{2+}$ signal. In support of this idea, Rimessi et al. showed that tumor transformation resulting from the oncogenic activation of the Harvey rat sarcoma viral oncogene homolog (H-RAS) (66) is accompanied by a progressive reduction in the amount of intracellular $\mathrm{Ca}^{2+}$ that is transferable to mitochondria. Furthermore, these authors also demonstrated that a controlled increase in the extracellular $\mathrm{Ca}^{2+}$ level causes an increase in the intracellular $\mathrm{Ca}^{2+}$ level, which impedes H-RAS-induced transformation (67).

The second most important inducers, which were previously mentioned, are ROS. The current findings on ROS-induced cell death and cancer inevitably lead to the following paradox: many cancer cells have higher basal ROS levels compared with normal cells, but cancer cells are highly resistant to cell death. One explanation for this paradox is that ROS also promote several hallmarks of cancer, such as proliferation, invasion, and metastasis [for more details, see in Ref. (68) and (69)]. Another explanation is that several cancer cell types have higher levels of antioxidants, which could inhibit ROS toxicity; specifically, increased levels of superoxide dismutase (SOD-2) and thioredoxin reductase 2 (TRX-2) were observed in mitochondria from cancer tissue samples (70-72).

Furthermore, an elevated ROS level may reduce the mPTP threshold for $\mathrm{Ca}^{2+}$. Therefore, the decrease in the $\mathrm{Ca}^{2+}$ level that occurs during cell transformation may allow the ROS level to increase without alerting the cellular regulatory mechanisms. Evading these regulatory mechanisms would then allow the tumor cell to undergo the cancer-promoting changes induced by a high ROS level.

\section{LEVELS OF mPTP COMPONENTS}

Another paradox concerning the involvement of the mPTP in cancer is related to the expression levels of its components. Studies in cancer cell lines and tumor models have shown that different mPTP proteins are overexpressed $(73,74)$. For example,

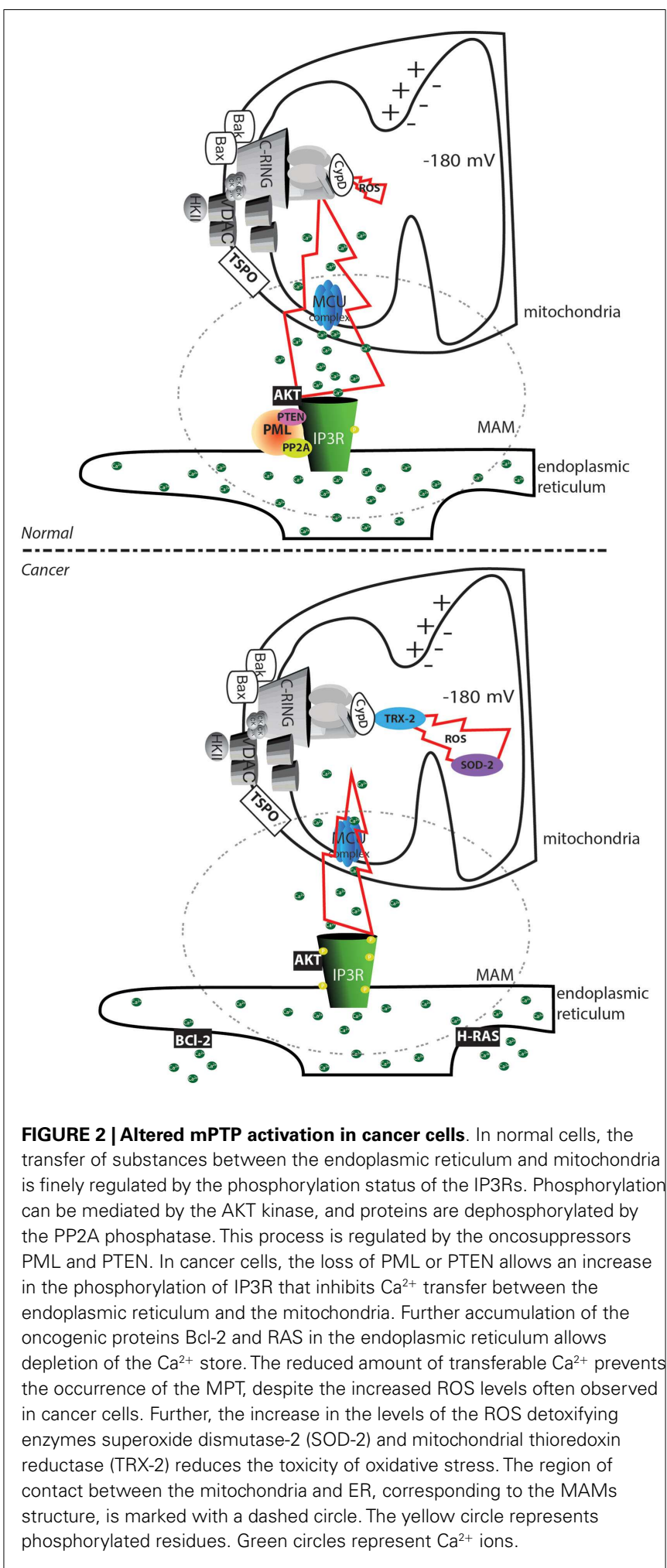

the expression levels of VDAC isoforms are significantly higher in malignant tumor cells (75), and there is a positive correlation between tumorigenesis and the expression level of TSPO, the ligand of which can induce apoptosis in cancer cells (76, 
77). Furthermore, the adenine nucleotide translocator ANT-2 is upregulated in renal tumors and transformed hepatocytes (78). This upregulation, however, may be explained by regulation of the metabolic status and may not be dependent on the MPT. Analogous to ANT-2 is HKII, the catalyst of the first step of glycolysis. This enzyme is located on the cytoplasmic side of the mitochondrial outer membrane, where it interacts with other MPTP regulators, and removing this enzyme from this location causes the MPTP to open $(79,80)$. The expression level of HKII is higher in several tumors (81-84). However, because of its role in glycolysis, the upregulation of HKII expression may be linked to the Warburg effect, which is generally observed in tumors and provides a metabolic advantage rather than specific resistance to apoptosis.

These findings suggest that the expression levels of the MPTP components are generally higher in tumors, and this increase is likely to enhance the probability of MPTP formation and cell death, in contrast to the reduced sensitivity to apoptosis that is typical of tumors. The solution to this enigma may be found within the Bcl-2 family of proteins.

The Bcl-2 family is a well-studied group of proteins involved in the regulation of apoptosis, necrosis, and autophagy $(85,86)$. Within this family, several anti-apoptotic members, such as Bcell lymphoma-extra large $(\mathrm{Bcl}-\mathrm{Xl})$ and myeloid cell leukemia 1 (Mcl-1), are overexpressed in cancer (87). Bcl-Xl has been shown to negatively regulate $\mathrm{mPTP}$ opening by directly interacting with VDAC (88) at the cytoplasmic side. More recently, the group of Jonas identified an unexpected mitochondrial-matrix-localized form of $\mathrm{Bcl}-\mathrm{Xl}$ that is able to interact with the $\beta$ subunit of ATP synthase to promote its synthetase activity and to inhibit mPTP opening in parallel [Figure 3; (89)].

Although the precise mechanism has not been elucidated, it has been shown that Mcl-1 plays a role in inhibiting the MPT (90). Furthermore, it has been proposed that the anti-apoptotic members Bcl-2, Bcl-Xl, and Mcl-1 interfere with the proapoptotic interactions induced by Bax and Bak (Figure 3). Specifically, it has been suggested that Bax and Bak positively regulate the opening of the mPTP $(15,34,91)$. Mutations in the Bax protein have been identified in gastric and colon cancer $(92,93)$, and its degradation is accelerated in prostate cancer (94). Missense mutations in Bak have been identified in late-stage gastrointestinal cancer (95). Unlike normal cells, pancreatic cancer cells are unable to properly increase Bak expression in response to stimuli, which suggests that the Bax-dependent apoptotic pathway is inhibited (96).

Therefore, it appears that an increase in the mPTP components in cancer is counteracted by an increase in negative regulators belonging to the Bcl-2 family or by inactivation of positive regulators belonging to the Bcl-2 family, which may be another strategy for evading MPT-induced cell death.

\section{CHAPERONE NETWORK AROUND THE MPTP}

The gold standard in MPT studies is the use of CsA as a potent inhibitor of the MPTP. This immunosuppressant is a target of CypD, a mitochondrial chaperone that is required for proper opening of the MPTP and that confers $\mathrm{Ca}^{2+}$ sensitivity to the complex. Although its mechanism has not yet been elucidated, it has been suggested that CypD promotes the rearrangement of the MPTP subunits to allow for channel formation because it is a chaperone

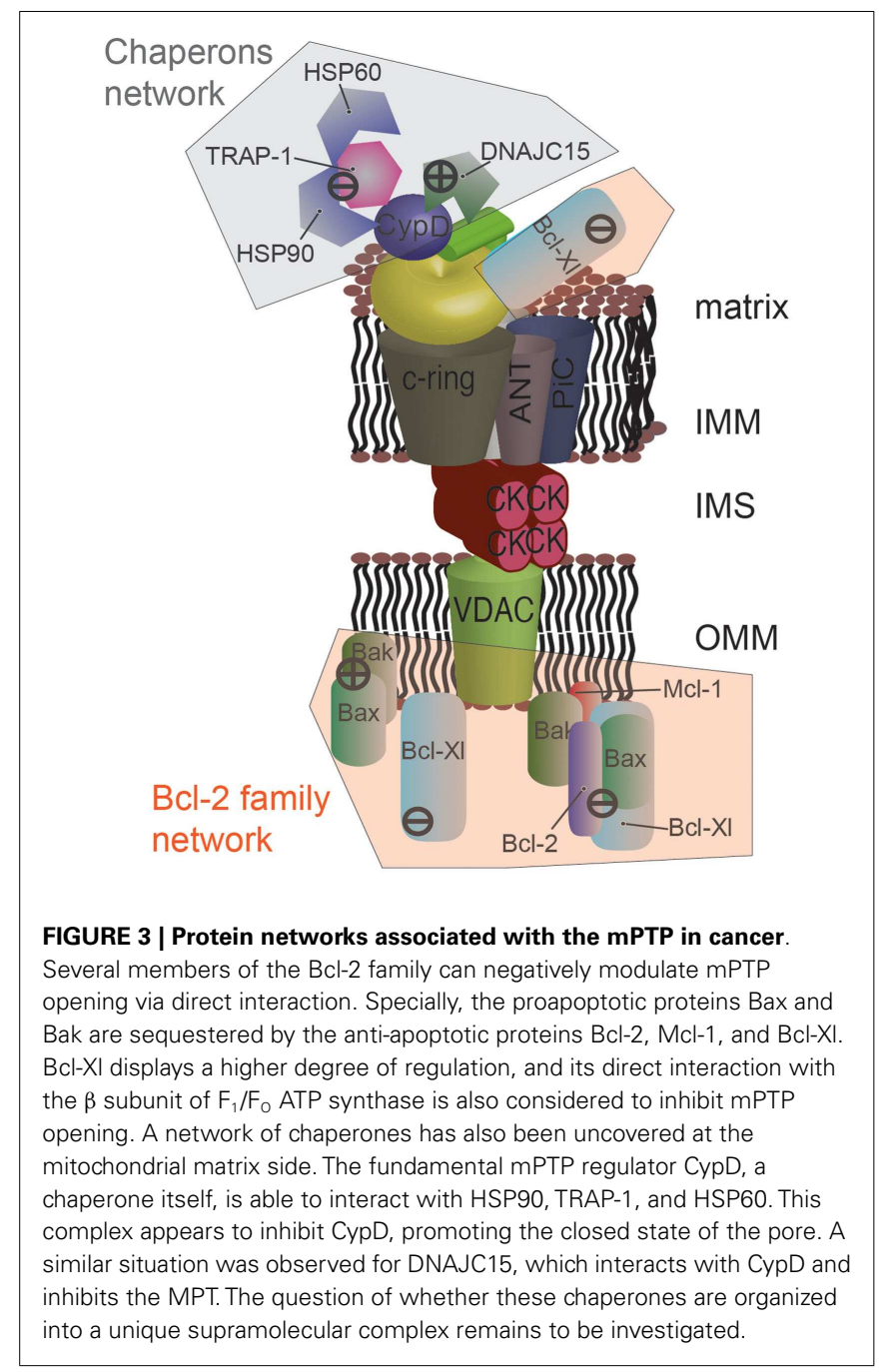

protein. Furthermore, other mitochondrial chaperones may also be involved in a similar mechanism.

Accordingly, heat shock protein 90 (HSP90) was found in a complex with TNF receptor-associated protein-1 (TRAP-1) and CypD (97). This complex appears only in tumors and inhibits apoptosis. Furthermore, the use of mitochondria-targeted ATPase antagonists is sufficient to block the protection provided by HSP90 and to restore the susceptibility of the cell to apoptosis. Although mPTP activity was not measured, it was speculated that this complex is part of a novel cytoprotective pathway that involves the MPT and is required for tumor growth in vivo (Figure 3). Another study detected the mitochondrial chaperone heat shock protein 60 (HSP60) in this same complex (98). This finding received significant interest because HSP60 is often overexpressed in tumors (99).

Recently, DnaJ homolog, subfamily C, member 15 (DnaJC15) has been implicated in control of the MPT. J proteins are chaperones that cooperate with heat shock protein 70 (HSP70) to direct proteins to specific intracellular locations, such as mitochondria, and DnaJC15 is part of the mitochondrial protein transport machinery. Ovarian and breast cancer cells from patients exposed 
to chemotherapy displayed reduced levels of DnaJC15 and showed enhanced resistance to the therapy. This resistance was attributed to methylation of CpG islands in the gene encoding DnaJC15. DnaJC15 has not been found to have a role in cell death or proliferation.

Sinah and D'Silva (100) demonstrated that DnaJC15 regulates MPTP activity by interacting with CypD (Figure 3). These authors observed that DnaJC15 overexpression induced spontaneous MPT, while its downregulation (as observed in cancer) reduced the sensitivity of $\mathrm{mPTP}$ opening when stimulated with cisplatin.

Thus, the notion is emerging that a complex chaperone network develops in the mitochondria of tumor cells that inhibits mPTP opening. The existence of this network would at least partially account for the different chaperone levels that are observed in several types of cancers (101) and would provide a new panel of pharmacological tools that could selectively target tumors and reduce the toxicity of the current anticancer strategies (102).

\section{AFFERENT SIGNALING TO THE mPTP}

A group of well-known oncogenes and oncosuppressors are able to modulate $\mathrm{Ca}^{2+}$ homeostasis to regulate induction of the MPT. Interestingly, some of these factors are able to localize to MAMs, potentially to increase the selectivity and efficiency of their regulatory effect. This is the case for AKT (103) and two oncosuppressors, PML (63), and PTEN (64). At these sites, AKT, PML, and PTEN appear to exist in a complex that interacts with and determines the phosphorylation status of the IP3R, which affects its channel activity (Figure 2). This model has received a significant amount of interest because AKT and PTEN are both members (with opposite functions) of the PI3K pathway, which is one the most well-studied survival signaling pathways and plays a critical role in resistance to anticancer therapies (104-106).

AKT may affect mPTP activity through another mechanism that is not directly related to $\mathrm{Ca}^{2+}$ signaling. AKT can induce the phosphorylation of GSK3 $\beta$, which results in its inactivation. GSK3 $\beta$ kinase has a significant stimulatory effect on the mPTP. Its inactivation by AKT strengthens the association between HKII and VDAC, causing inhibition of $\mathrm{mPTP}$ function and an increase in cell survival (107). Alterations in GSK3 $\beta$ have been found in several cancer types [for details, see in Ref. (108)]; furthermore, GSK3 $\beta$ is of significant interest because it could act as a convergence factor that allows survival signaling pathways to interact with the mPTP. In addition to the growth signals stimulated by AKT, the wingless integrated human homolog (WNT), protein kinase C (PKC), and extracellular signal-regulated kinase (ERK) pathways can also regulate GSK3 $\beta$ phosphorylation, which potentially connects the MPT to signals stimulated by growth factors, ligands of G proteincoupled receptors, and the extracellular matrix [Figure 4; (109, 110)].

To further emphasize the potential role of GSK3 $\beta$ in regulating the $\mathrm{mPTP}$ in cancers, the activation of GSK3$\beta$ causes the release of HKII from the OMM. The use of synthetic inhibitors showed that this event can induce cell death in cancer cell lines (79).

The epsilon isoform of PKC (PKCE) has been proposed to have a mechanism of action that is independent of GSK3 $\beta$. First, $\mathrm{PKC} \varepsilon$ was proposed to form a complex with VDAC1-HKII-ANT,

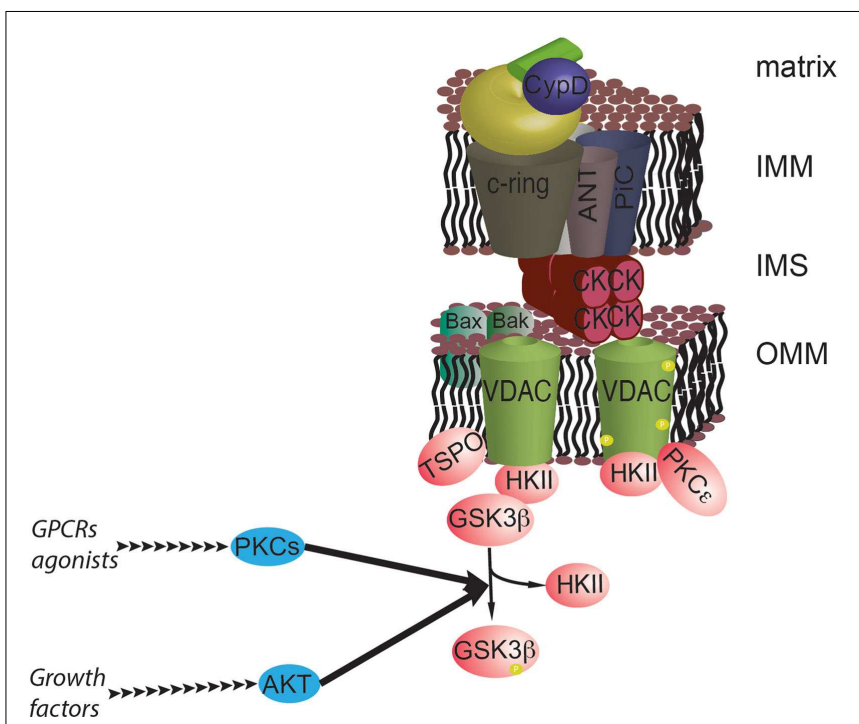

FIGURE 4 |The prosurvival pathway converges on the mPTP. GSK3 $\beta$ is a negative regulator of the MPTP, and its activity is inhibited by phosphorylation by AKT and PKCs. GSK3 $\beta$ functions as a hub for different survival signals at the interface with mPTP. In addition, PKC $\varepsilon$ can stabilize the interaction with HKII by phosphorylating VDAC.

thereby inducing VDAC1 phosphorylation and the consequent inhibition of $\mathrm{mPTP}$ activity (Figure 4). However, PKC $\varepsilon$ was also shown to reduce the $\mathrm{Ca}^{2+}$ content in the sarcoplasmic reticulum during preconditioning of cardiac tissue. This is likely to reduce the probability of mPTP induction during ischemia/reperfusion, conferring a mechanism for preconditioning-mediated cardioprotection (111). The question of whether this event could be relevant in the tumor environment has yet to be addressed.

mTOR, a negative regulator of autophagy, functions downstream of the AKT pathway. Targeting mTOR inhibits the mPTP to a similar extent as activating AKT and inactivating GSK3 $\beta$, and inhibition of mTOR enhances the binding of HKII to VDAC (112).

Thus, kinase cascades that are significantly activated in cancers can maintain HKII bound to the mitochondrial surface via inhibiting GSK3, thus keeping the MPTP closed. These events may contribute to the anti-apoptotic phenotype of tumor cells and to the development of resistance to therapies. In contrast, strategies directed at activating GSK3 may increase the sensitivity of mPTP opening and increase the probability of tumor regression (113).

\section{mPTP AND THE WARBURG EFFECT}

Mitochondrial permeability transition-driven cell death is closely associated with the hypoxia-induced ischemia that occurs in normal tissue as well as the consequent reperfusion injury. The current model proposes that during ischemia, the accumulation of lactate resulting from oxygen deprivation leads to a decrease in the $\mathrm{pH}$ and activation of the $\mathrm{Na}^{+} / \mathrm{H}^{+}$exchanger, which is required to buffer the cytoplasmic $\mathrm{pH}$. Accumulation of $\mathrm{Na}^{+}$is then prevented via the action of the $\mathrm{Na}^{+} / \mathrm{Ca}^{2+}$ exchanger, which increases the cytosolic $\mathrm{Ca}^{2+}$ concentration $\left(\left[\mathrm{Ca}^{2+}\right]_{c}\right)$. The accumulation of cytoplasmic $\mathrm{Ca}^{2+}$ is further increased by a reduction in the activity 
of the $\mathrm{Ca}^{2+}$ pumps located on the sarcoplasmic reticulum and sarcolemma because of the loss of ATP. Furthermore, the sustained loss of ATP leads to temporary accumulation of ADP, which is converted to adenine monophosphate (AMP) and adenosine and results in the accumulation of $\mathrm{Pi}$. It has been shown that $\mathrm{Pi}$ induces the MPT. During ischemia, cells accumulate MPT inducers $\left(\mathrm{Ca}^{2+}\right.$, $\mathrm{Pi}$ ) and lose one of the most important MPT inhibitors, ADP (114). The most detrimental effects, however, are not observed until reperfusion, when a significant amount of ROS is produced that definitively and dramatically induces the MPT and necrosis. Based on these findings, induction of the MPT has been monitored during myocardial (115) and brain reperfusion injury (116).

The unregulated growth of a solid tumor mass generates a hypoxic environment. This condition is not irreversible; rather, it is intermittent and characterized by cycles of hypoxia and reoxygenation (117). This condition should induce the same mechanism of mPTP opening that has been observed in the myocardium and brain and should thus reduce tumor size. These events, however, have not been observed in actual solid cancers, which suggests that a different protection mechanism is involved in these tumors.

One potential protection mechanism is related to the Warburg effect, which is the dramatic increase in glucose uptake and lactate fermentation observed in tumor masses $(118,119)$. Solid tumors display an extraordinary capacity for glucose uptake, which is a property that is exploited for the diagnosis of solid tumors. Glucose is converted to pyruvate, which is further reduced to lactate to complete the lactate fermentation process. These reactions occur even in the presence of functional mitochondria; thus, their purpose and significance remains controversial $(120,121)$. Nonetheless, the findings reported by Warburg have been confirmed by other groups and result in two main consequences for the MPT. First, the increase in glucose uptake allows for the continued synthesis of ATP through glycolysis, which impedes the depletion of adenine nucleotides and $\mathrm{Pi}$ accumulation that were described in the previous model. Second, the accumulation of lactate lowers the $\mathrm{pH}$, thus inhibiting the mPTP. This finding suggests that the Warburg effect alone may result in $\mathrm{mPTP}$ inhibition (Figure 5).

A more direct potential mechanism involves hypoxia-inducible factor $1 \alpha(\mathrm{HIF} 1 \alpha)$. HIF $1 \alpha$ is a heterodimeric protein that acts as an oxygen-level sensor because its degradation is prevented by ROS accumulation. Additionally, HIF1 $\alpha$ activates the transcription of genes that favor glycolysis and lactate fermentation while suppressing mitochondrial respiration [for further review, see in Ref. (122)]. The reduction in the mitochondrial potential resulting from a reduction in mitochondrial respiration inhibits $\mathrm{Ca}^{2+}$ uptake and the significant increase in ROS. Both of these events activate the MPTP (see above); however, because of its ability to stabilize HKII, the effect of HIF1 $\alpha$ on the MPT is even more direct (123). Gwak and colleagues demonstrated that hypoxia promotes the expression of HKII, which inhibits the mPTP through HIF1 $\alpha$ (Figure 5). Consistent with this finding, the selective inhibition of HKII induces apoptotic cell death, which is analogous to the results observed when HKII is induced to detach from mitochondria (79). Unfortunately, the authors did not directly demonstrate the involvement of the MPTP in this mechanism.

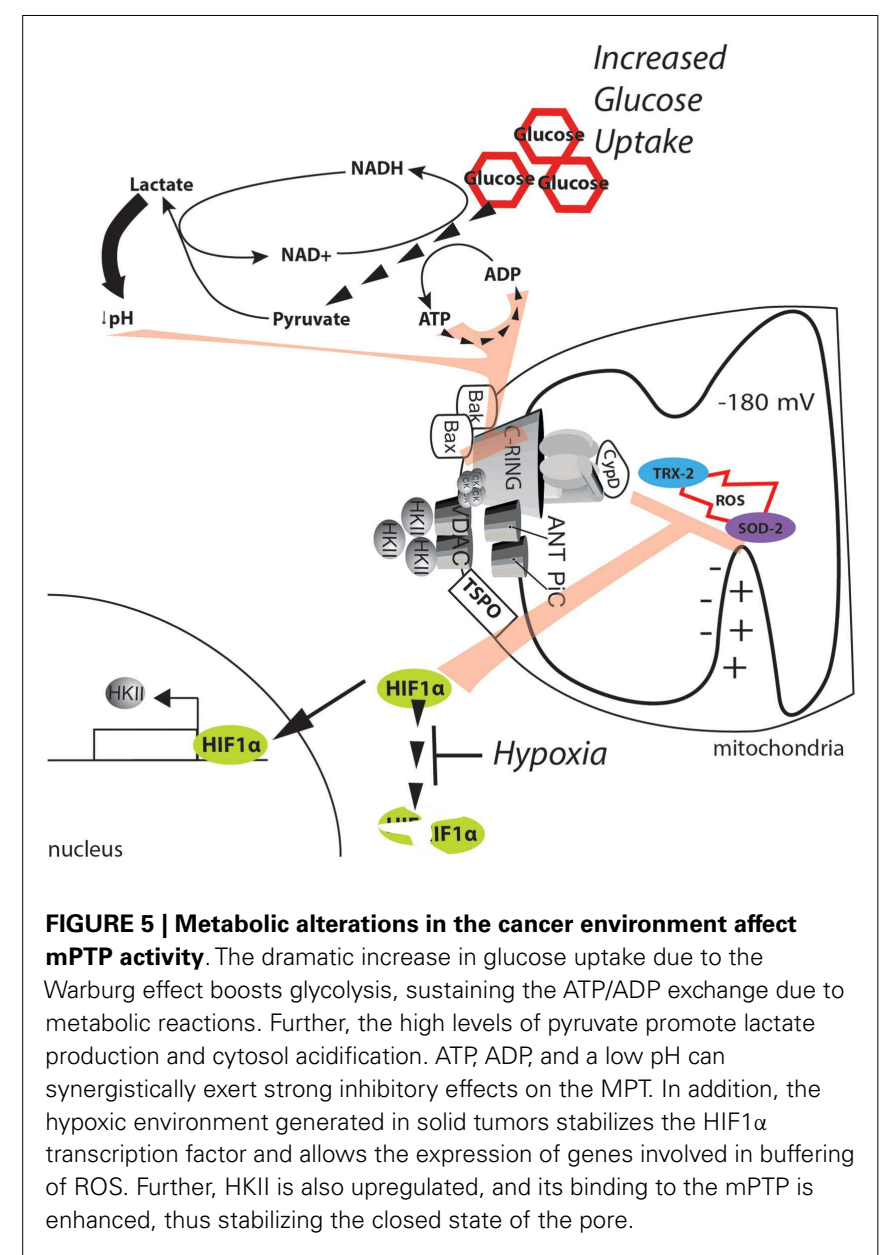

Older biochemical data indicate that when HKII is bound to the mPTP, glucose can induce mPTP inhibition; on the other hand, glucose-6-phosphate, which is the product of HKII, induces detachment of HKII from mitochondria (124). Because HIF1 $\alpha$ can promote both glucose uptake (by elevating the levels of the glucose transporter GLUT1) and its conversion through glycolytic flux, it can be speculated that elevation of HIF1 $\alpha$ in cancer will further inhibit mPTP activity by increasing the levels of glucose (to be considered as an inhibitor of mPTP) but can also impede the accumulation of glucose 6-phosphate (which can serve as an mPTP inducer) through the regulation of glycolytic enzymes and inhibition of pyruvate dehydrogenase (PDH).

Finally, the reduced oxygen levels in the tumor environment should decrease the activity of the respiratory chain and Complex I. We previously mentioned that Complex I inhibition can result in $\mathrm{mPTP}$ inhibition; thus, it can be postulated that hypoxia may impair mPTP activity via its effects on Complex I. However, it should be noted that the role of Complex I activity in cancer is controversial. Mutations in mitochondrial DNA that impair Complex I function reveal that the activity of Complex I is essential for stabilizing HIF $1 \alpha$ and for generating the Warburg phenotype (125). Concurrently, another group observed that overexpression of Ndil (a subunit of yeast Complex I with dehydrogenase activity) favors mitochondrial metabolism in breast cancer cells and 
reduces breast cancer tumor formation and metastasis (126). Both studies accounted for the effect on the NADH/NAD+ ratio: the first study indicated that a decrease in the NADH/NAD+ ratio could lead to a decrease in $\alpha$ ketoglutarate (required for the stabilization of HIF $1 \alpha$ ), and the second study showed that NAD+ could regulate mTORC1 and autophagy, leading to inhibition of tumor growth. It should be noted that in several types of cancer, mutations in mitochondrial DNA have been reported (127-130), and the ability of these mutations to increase ROS seems to confer an advantage to tumors, especially during metastasis formation (131).

Overall, the findings from previous studies suggest that inhibition of the MPTP plays a role in the resistance of solid tumors to hypoxic conditions.

\section{CONCLUDING REMARKS}

Because defects in the cell death pathway are considered a hallmark of tumor initiation and progression, the MPT is a potential target for rescuing oncogenic defects. In-depth studies on MPTP activity have been conducted to identify the factors that inhibit the activation of cell death pathways.

Functional mPTPs can be found in cancer cell lines, indicating that mPTPs are not completely inhibited in cancer. Furthermore, several structural elements of the pore are overexpressed and not downregulated in these cell lines. These findings are most likely the result of the paradoxical nature of the MPTP. More recent studies have proposed the existence of an "evolved aberrant conformation" of extremely efficient components that are indispensable for mitochondrial physiology (such as ion and solute transporters as well as chaperones).

Nevertheless, several mPTP regulatory mechanisms are impaired in tumors compared with the surrounding tissues. These alterations can be categorized as: (i) alterations in the concentrations of mPTP inducers (i.e., $\mathrm{Ca}^{2+}$ ), (ii) promotion or inhibition of regulators that interact directly with the MPTP (i.e., chaperone networks), (iii) desensitization through kinase signaling pathways, and (iv) inhibition mediated by metabolic changes. All of these mechanisms do not necessarily occur in the same tumor type; however, they are not necessarily independent and can integrate with each other.

Interestingly, the establishment of this variety of integrated mPTP inhibition mechanisms may be the result of an evolutionary process. Opening of the MPTP may have acted as a selection pressure that only permitted the proliferation of cells capable of evading the MPT induction mechanism.

It may be possible to generate such selection pressure via autophagy, the process by which cytoplasmic constituents are sequestered into double-membrane vesicles called autophagosomes and selectively degraded by fusion of the autophagosomes with lysosomes. Opening of the mPTP can lead to loss of $\Psi \mathrm{m}$, with subsequent swelling of the mitochondrial matrix.

It has been reported that damaged and depolarized mitochondria are sequestered into autophagic vacuoles in a selective form of autophagy called "mitophagy" (132, 133). In 1997, Lemaster's group initially proposed that the MPT could mediate the depolarization required for selective degradation of mitochondria through autophagy (134). These researchers observed spontaneous mitochondrial depolarization preceding organelle fusion with lysosomes (presumably through autophagosome and autophagolysosome formation), and the frequency of these events increased dramatically when autophagy was induced by serum starvation.

Strong support for this hypothesis was provided in a more recent study in which the authors showed that mitochondrial depolarization (induced by serum starvation) was dramatically inhibited by administration of the CypD inhibitor CsA. CsA administration, in addition to knocking down CypD, prevents mitochondrial sequestration into autophagosomes, indicating that serum starvation leads to mPTP opening that in turn drives selective mitochondrial degradation (here, the MPT was detected as mitochondrial depolarization, which, as previously stated, should be used carefully and in combination with the appropriate controls).

The connection between MPT and autophagy in cancer is less clear, mostly because knowledge regarding autophagy and cancer is scarce, and the data are controversial.

In fact, several autophagy genes have been found to be compromised in several types of cancers, and overexpression of some of these genes results in autophagy activation and growth inhibition (135-137). However, it has also been observed that nutritional stress (low availability of nutrients, oxygen, and mitogens) in the tumor environment leads to autophagy activation that in turn promotes tumor survival. Despite this finding, different studies have indicated that dysfunctional mitochondria accumulate in cancer, apparently due to dysfunctional mitophagy, which facilitates the accumulation of ROS (see above) and favors the metabolic reprograming that occurs in cancer (138-141).

Considering the previous findings regarding MPT and mitophagy, it could be speculated that an increase in the mPTP threshold occurs early in tumor transformation, impeding the spontaneous depolarization that should "mark" stressed mitochondria for selective degradation. This would lead to accumulation of mitochondria and a continuation of ROS generation, which in turn triggers the proliferative pathway for tumor formation.

Unfortunately, no studies have reported findings that are sufficient to validate this hypothesis; however, some studies on cancer stem cells (CSCs) have provided clear evidence. CSCs are cells that are able to undergo self-renewal and are committed to a cancer cell lineage, thus generating a tumor. The existence of these cells was initially hypothesized as part of a model that would explain the origins of tumor heterogeneity; however, their existence has finally been confirmed in several types of cancer (142-145), and they are now intensively being investigated. In a recent paper by Vega-Naredo and co-workers, several mitochondrial features were investigated during the differentiation of a cell line derived from a teratocarcinoma called P19 (146). This embryonic carcinoma cell line is pluripotent and can be induced in immortalized endodermal or mesodermal cells by retinoic acid. In this study, the authors observed that during the differentiation process, mPTPs switch from a more opened state to a more closed state. Although the effect of retinoic acid on mPTPs was not addressed, this study supports the possibility that cancer cells have evolved mechanisms to escape MPTP opening by desensitizing mPTPs. 
In addition, several strategies designed to rescue mPTP activity have shown significant success [for extensive reviews, see in Ref. (74, 147, 148)].

Overall, a growing body of evidence suggests that inhibition of the MPTP may be a protective mechanism for cancer cell survival and proliferation and that targeting the MPTP may be a promising strategy for improving anticancer therapies.

\section{ACKNOWLEDGMENTS}

This study was supported by the Italian Association for Cancer Research (AIRC); Telethon (GGP11139B); local funds from the University of Ferrara; and the Italian Ministry of Education, University and Research (COFIN, FIRB, and Futuro in Ricerca) to Paolo Pinton.

\section{REFERENCES}

1. Hunter DR, Haworth RA. The Ca2+-induced membrane transition in mitochondria. I. The protective mechanisms. Arch Biochem Biophys (1979) 195:453-9. doi:10.1016/0003-9861(79)90371-0

2. Crompton M, Costi A. A heart mitochondrial Ca2(+)-dependent pore of possible relevance to re-perfusion-induced injury. Evidence that ADP facilitates pore interconversion between the closed and open states. Biochem J (1990) 266:33-9.

3. Takeyama N, Matsuo N, Tanaka T. Oxidative damage to mitochondria is mediated by the $\mathrm{Ca}(2+)$-dependent inner-membrane permeability transition. Biochem J (1993) 294(Pt 3):719-25.

4. Javadov S, Karmazyn M. Cellular physiology biochemistry and biochemistry mitochondrial permeability transition pore opening as an endpoint to initiate cell death and as a putative target for cardioprotection. Cell Physiol Biochem (2007) 1:1-22. doi:10.1159/000103747

5. Hausenloy DJ, Boston-Griffiths EA, Yellon DM. Cyclosporin A and cardioprotection: from investigative tool to therapeutic agent. Br J Pharmacol (2012) 165:1235-45. doi:10.1111/j.1476-5381.2011.01700.x

6. Osman MM, Lulic D, Glover L, Stahl CE, Lau T, van Loveren H, et al. Cyclosporine-A as a neuroprotective agent against stroke: its translation from laboratory research to clinical application. Neuropeptides (2011) 45:359-68. doi:10.1016/j.npep.2011.04.002

7. Basso E, Fante L, Fowlkes J, Petronilli V, Forte MA, Bernardi P. Properties of the permeability transition pore in mitochondria devoid of cyclophilin D. J Biol Chem (2005) 280:18558-61. doi:10.1074/jbc.C500089200

8. Schinzel AC, Takeuchi O, Huang Z, Fisher JK, Zhou Z, Rubens J, et al. Cyclophilin $\mathrm{D}$ is a component of mitochondrial permeability transition and mediates neuronal cell death after focal cerebral ischemia. Proc Natl Acad Sci U S A (2005) 102:12005-10. doi:10.1073/pnas.0505294102

9. Kantrow SP, Piantadosi CA. Release of cytochrome $\mathrm{c}$ from liver mitochondria during permeability transition. Biochem Biophys Res Commun (1997) 232:669-71. doi:10.1006/bbrc.1997.6353

10. Susin SA, Lorenzo HK, Zamzami N, Marzo I, Snow BE, Brothers GM, et al. Molecular characterization of mitochondrial apoptosis-inducing factor. Nature (1999) 397:441-6. doi:10.1038/17135

11. Zhou LL, Zhou LY, Luo KQ, Chang DC. Smac/DIABLO and cytochrome c are released from mitochondria through a similar mechanism during UV-induced apoptosis. Apoptosis (2005) 10:289-99. doi:10.1007/s10495-005-0803-9

12. Davies AM, Hershman S, Stabley GJ, Hoek JB, Peterson J, Cahill A. A Ca2+induced mitochondrial permeability transition causes complete release of rat liver endonuclease $\mathrm{G}$ activity from its exclusive location within the mitochondrial intermembrane space. Identification of a novel endo-exonuclease activity residing within. Nucleic Acids Res (2003) 31:1364-73. doi:10.1093/nar/gkg205

13. Ellerby HM, Martin SJ, Ellerby LM, Naiem SS, Rabizadeh S, Salvesen GS, et al. Establishment of a cell-free system of neuronal apoptosis: comparison of premitochondrial, mitochondrial, and postmitochondrial phases. J Neurosci (1997) 17:6165-78.

14. Marchetti P, Castedo M, Susin SA, Zamzami N, Hirsch T, Macho A, et al. Mitochondrial permeability transition is a central coordinating event of apoptosis. J Exp Med (1996) 184:1155-60. doi:10.1084/jem.184.3.1155
15. Narita M, Shimizu S, Ito T, Chittenden T, Lutz RJ, Matsuda H, et al. Bax interacts with the permeability transition pore to induce permeability transition and cytochrome c release in isolated mitochondria. Proc Natl Acad Sci (1998) 95:14681-6. doi:10.1073/pnas.95.25.14681

16. Marzo I, Brenner C, Zamzami N, Jürgensmeier JM, Susin SA, Vieira HL, et al. Bax and adenine nucleotide translocator cooperate in the mitochondrial control of apoptosis. Science (1998) 281:2027-31. doi:10.1126/science.281.5385. 2027

17. Bonora M, Patergnani S, Rimessi A, De Marchi E, Suski JM, Bononi A, et al. ATP synthesis and storage. Purinergic Signal (2012) 8:343-57. doi:10.1007/s11302012-9305-8

18. Duchen MR, Leyssens A, Crompton M. Transient mitochondrial depolarizations reflect focal sarcoplasmic reticular calcium release in single rat cardiomyocytes. J Cell Biol (1998) 142:975-88. doi:10.1083/jcb.142.4.975

19. Zhao H, Yenari MA, Cheng D, Sapolsky RM, Steinberg GK. Biphasic cytochrome c release after transient global ischemia and its inhibition by hypothermia. J Cereb Blood Flow Metab (2005) 25:1119-29. doi:10.1038/sj. jcbfm. 9600111

20. Ott M, Robertson JD, Gogvadze V, Zhivotovsky B, Orrenius S. Cytochrome c release from mitochondria proceeds by a two-step process. Proc Natl Acad Sci U S A (2002) 99:1259-63. doi:10.1073/pnas.241655498

21. Zamaraeva MV, Sabirov RZ, Manabe K, Okada Y. Ca(2+)-dependent glycolysis activation mediates apoptotic ATP elevation in HeLa cells. Biochem Biophys Res Commun (2007) 363:687-93. doi:10.1016/j.bbrc.2007.09.019

22. Baines CP, Kaiser RA, Purcell NH, Blair NS, Osinska H, Hambleton MA, et al. Loss of cyclophilin D reveals a critical role for mitochondrial permeability transition in cell death. Nature (2005) 434:658-62. doi:10.1038/ nature 03434

23. Zhang Q, Huang W-D, Lv X-Y, Yang Y-M. Ghrelin protects H9c2 cells from hydrogen peroxide-induced apoptosis through NF- $\mathrm{B}$ and mitochondriamediated signaling. Eur J Pharmacol (2011) 654:142-9. doi:10.1016/j.ejphar. 2010.12.011

24. Gechev TS, Hille J. Hydrogen peroxide as a signal controlling plant programmed cell death. J Cell Biol (2005) 168:17-20. doi:10.1083/jcb.200409170

25. Zhang Z, Zheng L, Zhao Z, Shi J, Wang X, Huang J. Grape seed proanthocyanidins inhibit $\mathrm{H} 2 \mathrm{O} 2$-induced osteoblastic MC3T3-E1 cell apoptosis via ameliorating H2O2-induced mitochondrial dysfunction. J Toxicol Sci (2014) 39:803-13. doi:10.2131/jts.39.803

26. Li R, Yan G, Li Q, Sun H, Hu Y, Sun J, et al. MicroRNA-145 protects cardiomyocytes against hydrogen peroxide (H2O2)-induced apoptosis through targeting the mitochondria apoptotic pathway. PLoS One (2012) 7:e44907. doi:10.1371/journal.pone.0044907

27. Marchi S, Patergnani S, Pinton P. The endoplasmic reticulum-mitochondria connection: one touch, multiple functions. Biochim Biophys Acta (2014) 1837:461-9. doi:10.1016/j.bbabio.2013.10.015

28. Patergnani S, Suski JM, Agnoletto C, Bononi A, Bonora M, De Marchi E, et al. Calcium signaling around mitochondria associated membranes (MAMs). Cell Commun Signal (2011) 9:19. doi:10.1186/1478-811X-9-19

29. Giorgi C, Romagnoli A, Pinton P, Rizzuto R. Ca2 + signaling, mitochondria and cell death. Curr Mol Med (2008) 8:119-30. doi:10.2174/156652408783769571

30. Giorgi C, Baldassari F, Bononi A, Bonora M, De Marchi E, Marchi S, et al. Mitochondrial $\mathrm{Ca}(2+)$ and apoptosis. Cell Calcium (2012) 52:36-43. doi:10.1016/j.ceca.2012.02.008

31. Marchi S, Lupini L, Patergnani S, Rimessi A, Missiroli S, Bonora M, et al. Downregulation of the mitochondrial calcium uniporter by cancer-related miR-25. Curr Biol (2013) 23:58-63. doi:10.1016/j.cub.2012.11.026

32. Shoshan-Barmatz V, Mizrachi D. VDAC1: from structure to cancer therapy. Front Oncol (2012) 2:164. doi:10.3389/fonc.2012.00164

33. Kroemer G, Galluzzi L, Brenner C. Mitochondrial membrane permeabilization in cell death. Physiol Rev (2007) 87:99-163. doi:10.1152/physrev.00013.2006

34. Karch J, Kwong JQ, Burr AR, Sargent MA, Elrod JW, Peixoto PM, et al. Bax and Bak function as the outer membrane component of the mitochondrial permeability pore in regulating necrotic cell death in mice. Elife (2013) 2:e00772. doi:10.7554/eLife.00772

35. Scorrano L, Oakes SA, Opferman JT, Cheng EH, Sorcinelli MD, Pozzan T, et al. BAX and BAK regulation of endoplasmic reticulum $\mathrm{Ca} 2+$ : a control point for apoptosis. Science (2003) 300:135-9. doi:10.1126/science.1081208

36. Schroers A, Krämer R, Wohlrab H. The reversible antiport-uniport conversion of the phosphate carrier from yeast mitochondria depends on the presence 
of a single cysteine. J Biol Chem (1997) 272:10558-64. doi:10.1074/jbc.272.16. 10558

37. Leung AWC, Varanyuwatana P, Halestrap AP. The mitochondrial phosphate carrier interacts with cyclophilin D and may play a key role in the permeability transition. J Biol Chem (2008) 283:26312-23. doi:10.1074/jbc.M805235200

38. Alcalá S, Klee M, Fernández J, Fleischer A, Pimentel-Muiños FX. A highthroughput screening for mammalian cell death effectors identifies the mitochondrial phosphate carrier as a regulator of cytochrome c release. Oncogene (2008) 27:44-54. doi:10.1038/sj.onc.1210600

39. Varanyuwatana P, Halestrap AP. The roles of phosphate and the phosphate carrier in the mitochondrial permeability transition pore. Mitochondrion (2012) 12:120-5. doi:10.1016/j.mito.2011.04.006

40. Gutiérrez-Aguilar M, Douglas DL, Gibson AK, Domeier TL, Molkentin JD, Baines CP. Genetic manipulation of the cardiac mitochondrial phosphate carrier does not affect permeability transition. J Mol Cell Cardiol (2014) 72:316-25. doi:10.1016/j.yjmcc.2014.04.008

41. Kwong JQ, Davis J, Baines CP, Sargent MA, Karch J, Wang X, et al. Genetic deletion of the mitochondrial phosphate carrier desensitizes the mitochondrial permeability transition pore and causes cardiomyopathy. Cell Death Differ (2014) 21:1209-17. doi:10.1038/cdd.2014.36

42. Li B, Chauvin C, De Paulis D, De Oliveira F, Gharib A, Vial G, et al. Inhibition of complex I regulates the mitochondrial permeability transition through a phosphate-sensitive inhibitory site masked by cyclophilin D. Biochim Biophys Acta (2012) 1817:1628-34. doi:10.1016/j.bbabio.2012.05.011

43. Fontaine E, Eriksson O, Ichas F, Bernardi P. Regulation of the permeability transition pore in skeletal muscle mitochondria. Modulation by electron flow through the respiratory chain complex i. J Biol Chem (1998) 273:12662-8. doi:10.1074/jbc.273.20.12662

44. Batandier C, Leverve X, Fontaine E. Opening of the mitochondrial permeability transition pore induces reactive oxygen species production at the level of the respiratory chain complex I. J Biol Chem (2004) 279:17197-204. doi:10.1074/jbc.M310329200

45. Chinopoulos C, Konràd C, Kiss G, Metelkin E, Töröcsik B, Zhang SF, et al. Modulation of F0F1-ATP synthase activity by cyclophilin D regulates matrix adenine nucleotide levels. FEBS J (2011) 278:1112-25. doi:10.1111/j.17424658.2011.08026.x

46. Bonora M, Wieckowski MR, Chinopoulos C, Kepp O, Kroemer G, Galluzzi L, et al. Molecular mechanisms of cell death: central implication of ATP synthase in mitochondrial permeability transition. Oncogene (2014). doi:10.1038/onc.2014.96

47. Morciano G, Giorgi C, Bonora M, Punzetti S, Pavasini R, Wieckowski MR, et al. Molecular identity of the mitochondrial permeability transition pore and its role in ischemia-reperfusion injury. J Mol Cell Cardiol (2014). doi:10.1016/j. yjmcc.2014.08.015

48. Giorgio V, von Stockum S, Antoniel M, Fabbro A, Fogolari F, Forte M, et al. Dimers of mitochondrial ATP synthase form the permeability transition pore. Proc Natl Acad Sci U S A (2013) 110:5887-92. doi:10.1073/pnas.1217823110

49. Giorgio V, Bisetto E, Soriano ME, Dabbeni-Sala F, Basso E, Petronilli V, et al. Cyclophilin D modulates mitochondrial F0F1-ATP synthase by interacting with the lateral stalk of the complex. J Biol Chem (2009) 284:33982-8. doi:10.1074/jbc.M109.020115

50. Bonora M, Bononi A, De Marchi E, Giorgi C, Lebiedzinska M, Marchi S, et al. Role of the c subunit of the FO ATP synthase in mitochondrial permeability transition. Cell Cycle (2013) 12:674-83. doi:10.4161/cc.23599

51. De Marchi E, Bonora M, Giorgi C, Pinton P. The mitochondrial permeability transition pore is a dispensable element for mitochondrial calcium efflux. Cell Calcium (2014) 56:1-13. doi:10.1016/j.ceca.2014.03.004

52. Azarashvili T, Odinokova I, Bakunts A, Ternovsky V, Krestinina O, Tyynelä $\mathrm{J}$, et al. Potential role of subunit $\mathrm{c}$ of F0F1-ATPase and subunit $\mathrm{c}$ of storage body in the mitochondrial permeability transition. Effect of the phosphorylation status of subunit $c$ on pore opening. Cell Calcium (2014) 55:69-77. doi:10.1016/j.ceca.2013.12.002

53. Alavian KN, Beutner G, Lazrove E, Sacchetti S, Park H-A, Licznerski P, et al. An uncoupling channel within the c-subunit ring of the F1FO ATP synthase is the mitochondrial permeability transition pore. Proc Natl Acad Sci U S A (2014) 111(29):10580-5. doi:10.1073/pnas.1401591111

54. Hanahan D, Weinberg RA. Hallmarks of cancer: the next generation. Cell (2011) 144:646-74. doi:10.1016/j.cell.2011.02.013
55. Zhang D, Lu C, Whiteman M, Chance B, Armstrong JS. The mitochondrial permeability transition regulates cytochrome $c$ release for apoptosis during endoplasmic reticulum stress by remodeling the cristae junction. J Biol Chem (2008) 283:3476-86. doi:10.1074/jbc.M707528200

56. Zunino SJ, Storms DH. Resveratrol-induced apoptosis is enhanced in acute lymphoblastic leukemia cells by modulation of the mitochondrial permeability transition pore. Cancer Lett (2006) 240:123-34. doi:10.1016/j.canlet.2005. 09.001

57. Pinton P, Ferrari D, Rapizzi E, Di Virgilio F, Pozzan T, Rizzuto R. The Ca2+ concentration of the endoplasmic reticulum is a key determinant of ceramideinduced apoptosis: significance for the molecular mechanism of Bcl-2 action. EMBO J (2001) 20:2690-701. doi:10.1093/emboj/20.11.2690

58. Baumgartner HK, Gerasimenko JV, Thorne C, Ferdek P, Pozzan T, Tepikin $\mathrm{AV}$, et al. Calcium elevation in mitochondria is the main $\mathrm{Ca} 2+$ requirement for mitochondrial permeability transition pore (mPTP) opening. J Biol Chem (2009) 284:20796-803. doi:10.1074/jbc.M109.025353

59. Giorgi C, De Stefani D, Bononi A, Rizzuto R, Pinton P. Structural and functional link between the mitochondrial network and the endoplasmic reticulum. Int J Biochem Cell Biol (2009) 41:1817-27. doi:10.1016/j.biocel.2009.04.010

60. Bernardi R, Pandolfi PP. A dialog on the first 20 years of PML research and the next 20 ahead. Front Oncol (2014) 4:23. doi:10.3389/fonc.2014.00023

61. Pulido R, Baker SJ, Barata JT, Carracedo A, Cid VJ, Chin-Sang ID, et al. A unified nomenclature and amino acid numbering for human PTEN. Sci Signal (2014) 7:e15. doi:10.1126/scisignal.2005560

62. Marchi S, Pinton P. The mitochondrial calcium uniporter complex: molecular components, structure and physiopathological implications. J Physiol (2014) 592:829-39. doi:10.1113/jphysiol.2013.268235

63. Giorgi C, Ito K, Lin H, Santangelo C, Wieckowski MR, Lebiedzinska M, et al. PML regulates apoptosis at endoplasmic reticulum by modulating calcium release. Science (2010) 330:1247-51. doi:10.1126/science.1189157

64. Bononi A, Bonora M, Marchi S, Missiroli S, Poletti F, Giorgi C, et al. Identification of PTEN at the ER and MAMs and its regulation of $\mathrm{Ca}(2+)$ signaling and apoptosis in a protein phosphatase-dependent manner. Cell Death Differ (2013) 20:1631-43. doi:10.1038/cdd.2013.77

65. Pinton P, Ferrari D, Magalhães P, Schulze-Osthoff K, Di Virgilio F, Pozzan $\mathrm{T}$, et al. Reduced loading of intracellular $\mathrm{Ca}(2+)$ stores and downregulation of capacitative $\mathrm{Ca}(2+)$ influx in Bcl-2-overexpressing cells. J Cell Biol (2000) 148:857-62. doi:10.1083/jcb.148.5.857

66. Kang J, Pervaiz S. Crosstalk between Bcl-2 family and Ras family small GTPases: potential cell fate regulation? Front Oncol (2012) 2:206. doi:10.3389/fonc.2012. 00206

67. Rimessi A, Marchi S, Patergnani S, Pinton P. H-Ras-driven tumoral maintenance is sustained through caveolin-1-dependent alterations in calcium signaling. Oncogene (2014) 33(18):2329-40. doi:10.1038/onc.2013.192

68. Gupta SC, Hevia D, Patchva S, Park B, Koh W, Aggarwal BB. Upsides and downsides of reactive oxygen species for cancer: the roles of reactive oxygen species in tumorigenesis, prevention, and therapy. Antioxid Redox Signal (2012) 16:1295-322. doi:10.1089/ars.2011.4414

69. Yang Y, Karakhanova S, Werner J, Bazhin AV. Reactive oxygen species in cancer biology and anticancer therapy. Curr Med Chem (2013) 20:3677-92. doi:10.2174/0929867311320999165

70. Dvorakova K, Payne CM, Tome ME, Briehl MM, Vasquez MA, Waltmire CN, et al. Molecular and cellular characterization of imexon-resistant RPMI8226/I myeloma cells. Mol Cancer Ther (2002) 1:185-95. Available from: http://mct. aacrjournals.org/content/1/3/185.long

71. Biaglow JE, Miller RA. The thioredoxin reductase/thioredoxin system: novel redox targets for cancer therapy. Cancer Biol Ther (2005) 4:6-13. doi:10.4161/ cbt.4.1.1434

72. Pani G, Colavitti R, Bedogni B, Fusco S, Ferraro D, Borrello S, et al. Mitochondrial superoxide dismutase: a promising target for new anticancer therapies. Curr Med Chem (2004) 11:1299-308. doi:10.2174/0929867043365297

73. Brenner C, Grimm S. The permeability transition pore complex in cancer cell death. Oncogene (2006) 25:4744-56. doi:10.1038/sj.onc.1209609

74. Fulda S, Galluzzi L, Kroemer G. Targeting mitochondria for cancer therapy. Nat Rev Drug Discov (2010) 9:447-64. doi:10.1038/nrd3137

75. Shinohara Y, Ishida T, Hino M, Yamazaki N, Baba Y, Terada H. Characterization of porin isoforms expressed in tumor cells. Eur J Biochem (2000) 267:6067-73. doi:10.1046/j.1432-1327.2000.01687.x 
76. Beinlich A, Strohmeier R, Kaufmann M, Kuhl H. Relation of cell proliferation to expression of peripheral benzodiazepine receptors in human breast cancer cell lines. Biochem Pharmacol (2000) 60:397-402. doi:10.1016/S0006-2952(00) 00325-7

77. Maaser K, Höpfner M, Jansen A, Weisinger G, Gavish M, Kozikowski AP, et al. Specific ligands of the peripheral benzodiazepine receptor induce apoptosis and cell cycle arrest in human colorectal cancer cells. Br J Cancer (2001) 85:1771-80. doi:10.1054/bjoc.2001.2181

78. Faure Vigny H, Heddi A, Giraud S, Chautard D, Stepien G. Expression of oxidative phosphorylation genes in renal tumors and tumoral cell lines. $\mathrm{Mol}$ Carcinog (1996) 16:165-72. doi:10.1002/(SICI)1098-2744(199607)16:3<165: :AID-MC7>3.0.CO;2-G

79. Chiara F, Castellaro D, Marin O, Petronilli V, Brusilow WS, Juhaszova M, et al. Hexokinase II detachment from mitochondria triggers apoptosis through the permeability transition pore independent of voltage-dependent anion channels. PLoS One (2008) 3:e1852. doi:10.1371/journal.pone.0001852

80. Beutner G, Rück A, Riede B, Welte W, Brdiczka D. Complexes between kinases, mitochondrial porin and adenylate translocator in rat brain resemble the permeability transition pore. FEBS Lett (1996) 396:189-95. doi:10.1016/00145793(96)01092-7

81. Shinohara Y, Shima A, Kamida M, Terada H. Uncoupling protein is expressed in liver mitochondria of cold-exposed and newborn rats. FEBS Lett (1991) 293:173-4. doi:10.1016/0014-5793(91)81179-C

82. Rempel A, Mathupala SP, Griffin CA, Hawkins AL, Pedersen PL. Glucose catabolism in cancer cells: amplification of the gene encoding type II hexokinase. Cancer Res (1996) 56:2468-71.

83. Azoulay-Zohar H, Israelson A, Abu-Hamad S, Shoshan-Barmatz V. In selfdefence: hexokinase promotes voltage-dependent anion channel closure and prevents mitochondria-mediated apoptotic cell death. Biochem J (2004) 377:347-55. doi:10.1042/BJ20031465

84. Gudnason V, Ingvarsson S, Jonasdottir A, Andresdottir V, Egilsson V. Isoenzyme pattern and subcellular localization of hexokinases in human breast cancer and nonpathological breast tissue. Int J Cancer (1984) 34:63-6. doi:10.1002/ijc.2910340111

85. Yip KW, Reed JC. Bcl-2 family proteins and cancer. Oncogene (2008) 27:6398-406. doi:10.1038/onc.2008.307

86. Nikoletopoulou V, Markaki M, Palikaras K, Tavernarakis N. Crosstalk between apoptosis, necrosis and autophagy. Biochim Biophys Acta (2013) 1833:3448-59. doi:10.1016/j.bbamcr.2013.06.001

87. Quinn BA, Dash R, Azab B, Sarkar S, Das SK, Kumar S, et al. Targeting Mcl1 for the therapy of cancer. Expert Opin Investig Drugs (2011) 20:1397-411. doi:10.1517/13543784.2011.609167

88. Arbel N, Ben-Hail D, Shoshan-Barmatz V. Mediation of the antiapoptotic activity of Bcl-xL protein upon interaction with VDAC1 protein. J Biol Chem (2012) 287:23152-61. doi:10.1074/jbc.M112.345918

89. Alavian KN, Li H, Collis L, Bonanni L, Zeng L, Sacchetti S, et al. Bcl-xL regulates metabolic efficiency of neurons through interaction with the mitochondrial F1FO ATP synthase. Nat Cell Biol (2011) 13:1224-33. doi:10.1038/ ncb2330

90. Thomas RL, Roberts DJ, Kubli DA, Lee Y, Quinsay MN, Owens JB, et al. Gustafsson ÅB. Loss of MCL-1 leads to impaired autophagy and rapid development of heart failure. Genes Dev (2013) 27:1365-77. doi:10.1101/gad.215871.113

91. Brenner C, Cadiou H, Vieira HL, Zamzami N, Marzo I, Xie Z, et al. Bcl-2 and Bax regulate the channel activity of the mitochondrial adenine nucleotide translocator. Oncogene (2000) 19:329-36. doi:10.1038/sj.onc.1203298

92. Rampino N. Somatic Frameshift mutations in the BAX gene in colon cancers of the microsatellite mutator phenotype. Science (1997) 275:967-9. doi:10.1126/science.275.5302.967

93. Ionov Y, Yamamoto H, Krajewski S, Reed JC, Perucho M. Mutational inactivation of the proapoptotic gene BAX confers selective advantage during tumor clonal evolution. Proc Natl Acad Sci U S A (2000) 97:10872-7. doi:10.1073/pnas.190210897

94. Li B, Dou QP. Bax degradation by the ubiquitin/proteasome-dependent pathway: involvement in tumor survival and progression. Proc Natl Acad Sci U S A (2000) 97:3850-5. doi:10.1073/pnas.070047997

95. Kondo S, Shinomura Y, Miyazaki Y, Kiyohara T, Tsutsui S, Kitamura S, et al. Mutations of the bak gene in human gastric and colorectal cancers. Cancer Res (2000) 60:4328-30. Available from: http://cancerres.aacrjournals.org/content/ $60 / 16 / 4328 . l o n g$
96. Graber HU, Friess H, Zimmermann A, Korc M, Adler G, Schmid R, et al. Bak expression and cell death occur in peritumorous tissue but not in pancreatic cancer cells. J Gastrointest Surg (1999) 3:74-80. doi:10.1016/S1091-255X(99) 80012-2

97. Kang BH, Plescia J, Dohi T, Rosa J, Doxsey SJ, Altieri DC. Regulation of tumor cell mitochondrial homeostasis by an organelle-specific Hsp90 chaperone network. Cell (2007) 131:257-70. doi:10.1016/j.cell.2007.08.028

98. Ghosh JC, Siegelin MD, Dohi T, Altieri DC. Heat shock protein 60 regulation of the mitochondrial permeability transition pore in tumor cells. Cancer Res (2010) 70:8988-93. doi:10.1158/0008-5472.CAN-10-2225

99. Ghosh JC, Dohi T, Kang BH, Altieri DC. Hsp60 regulation of tumor cell apoptosis. J Biol Chem (2008) 283:5188-94. doi:10.1074/jbc.M705904200

100. Sinha D, D'Silva P. Chaperoning mitochondrial permeability transition: regulation of transition pore complex by a J-protein, DnaJC15. Cell Death Dis (2014) 5:e1101. doi:10.1038/cddis.2014.72

101. Rappa F, Farina F, Zummo G, David S, Campanella C, Carini F, et al. HSPmolecular chaperones in cancer biogenesis and tumor therapy: an overview. Anticancer Res (2012) 32:5139-50. Available from: http://ar.iiarjournals.org/ content/32/12/5139.long

102. Kang BH, Altieri DC. Compartmentalized cancer drug discovery targeting mitochondrial Hsp90 chaperones. Oncogene (2009) 28:3681-8. doi:10.1038/ onc. 2009.227

103. Marchi S, Rimessi A, Giorgi C, Baldini C, Ferroni L, Rizzuto R, et al. Akt kinase reducing endoplasmic reticulum $\mathrm{Ca} 2+$ release protects cells from $\mathrm{Ca} 2+-$ dependent apoptotic stimuli. Biochem Biophys Res Commun (2008) 375:501-5. doi:10.1016/j.bbrc.2008.07.153

104. Slomovitz BM, Coleman RL. The PI3K/AKT/mTOR pathway as a therapeutic target in endometrial cancer. Clin Cancer Res (2012) 18:5856-64. doi:10.1158/1078-0432.CCR-12-0662

105. Fresno Vara JA, Casado E, de Castro J, Cejas P, Belda-Iniesta C, GonzálezBarón M. PI3K/Akt signalling pathway and cancer. Cancer Treat Rev (2004) 30:193-204. doi:10.1016/j.ctrv.2003.07.007

106. Wolin EM. PI3K/Akt/mTOR pathway inhibitors in the therapy of pancreatic neuroendocrine tumors. Cancer Lett (2013) 335:1-8. doi:10.1016/j.canlet. 2013.02.016

107. Juhaszova M, Zorov DB, Kim S-H, Pepe S, Fu Q, Fishbein KW, et al. Glycogen synthase kinase-3beta mediates convergence of protection signaling to inhibit the mitochondrial permeability transition pore. J Clin Invest (2004) 113:1535-49. doi:10.1172/JCI200419906

108. Luo J. Glycogen synthase kinase 3beta (GSK3beta) in tumorigenesis and cancer chemotherapy. Cancer Lett (2009) 273:194-200. doi:10.1016/j.canlet.2008.05 045

109. Rasola A, Sciacovelli M, Chiara F, Pantic B, Brusilow WS, Bernardi P. Activation of mitochondrial ERK protects cancer cells from death through inhibition of the permeability transition. Proc Natl Acad Sci U S A (2010) 107:726-31. doi:10.1073/pnas.0912742107

110. Baines CP, Song C-X, Zheng Y-T, Wang G-W, Zhang J, Wang O-L, et al. Protein kinase cepsilon interacts with and inhibits the permeability transition pore in cardiac mitochondria. Circ Res (2003) 92:873-80. doi:10.1161/01.RES. $0000069215.36389 .8 \mathrm{D}$

111. Yamamura K, Steenbergen C, Murphy E. Protein kinase C and preconditioning: role of the sarcoplasmic reticulum. Am J Physiol Heart Circ Physiol (2005) 289:H2484-90. doi:10.1152/ajpheart.00590.2005

112. Kim JE, He Q, Chen Y, Shi C, Yu K. mTOR-targeted therapy: differential perturbation to mitochondrial membrane potential and permeability transition pore plays a role in therapeutic response. Biochem Biophys Res Commun (2014) 447:184-91. doi:10.1016/j.bbrc.2014.03.124

113. Chiara F, Rasola A. GSK-3 and mitochondria in cancer cells. Front Oncol (2013) 3:16. doi:10.3389/fonc.2013.00016

114. Crompton M. The mitochondrial permeability transition pore and its role in cell death. Biochem J (1999) 341(Pt 2):233-49. doi:10.1042/0264-6021: 3410233

115. Halestrap AP, Connern CP, Griffiths EJ, Kerr PM. Cyclosporin A binding to mitochondrial cyclophilin inhibits the permeability transition pore and protects hearts from ischaemia/reperfusion injury. Mol Cell Biochem (1997) 174:167-72. doi:10.1023/A:1006879618176

116. Li J, Ma X, Yu W, Lou Z, Mu D, Wang Y, et al. Reperfusion promotes mitochondrial dysfunction following focal cerebral ischemia in rats. PLoS One (2012) 7:e46498. doi:10.1371/journal.pone.0046498 
117. Toffoli S, Michiels C. Intermittent hypoxia is a key regulator of cancer cell and endothelial cell interplay in tumours. FEBS J (2008) 275:2991-3002. doi:10.1111/j.1742-4658.2008.06454.x

118. Warburg O, Wind F, Negelein E. The metabolism of tumors in the body. J Gen Physiol (1927) 8:519-30. doi:10.1085/jgp.8.6.519

119. Boland ML, Chourasia AH, Macleod KF. Mitochondrial dysfunction in cancer Front Oncol (2013) 3:292. doi:10.3389/fonc.2013.00292

120. Weinhouse S. The Warburg hypothesis fifty years later. Z Krebsforsch Klin Onkol Cancer Res Clin Oncol (1976) 87:115-26. doi:10.1007/BF00284370

121. Ferreira LMR. Cancer metabolism?: the Warburg effect today. Exp Mol Pathol (2010) 89:372-80. doi:10.1016/j.yexmp.2010.08.006

122. Gogvadze V, Orrenius S, Zhivotovsky B. Mitochondria in cancer cells: what is so special about them? Trends Cell Biol (2008) 18:165-73. doi:10.1016/j.tcb. 2008.01.006

123. Gwak G-Y, Yoon J-H, Kim KM, Lee H-S, Chung JW, Gores GJ. Hypoxia stimulates proliferation of human hepatoma cells through the induction of hexokinase II expression. J Hepatol (2005) 42:358-64. doi:10.1016/j.jhep.2004.11.020

124. Beutner G, Rück A, Riede B, Brdiczka D. Complexes between porin, hexokinase, mitochondrial creatine kinase and adenylate translocator display properties of the permeability transition pore. Implication for regulation of permeability transition by the kinases. Biochim Biophys Acta (1998) 1368:7-18 doi:10.1016/S0005-2736(97)00175-2

125. Calabrese C, Iommarini L, Kurelac I, Calvaruso MA, Capristo M, Lollini P$\mathrm{L}$, et al. Respiratory complex $\mathrm{I}$ is essential to induce a Warburg profile in mitochondria-defective tumor cells. Cancer Metab (2013) 1:11. doi:10.1186/ 2049-3002-1-11

126. Santidrian AF, Matsuno-Yagi A, Ritland M, Seo BB, LeBoeuf SE, Gay LJ, et al. Mitochondrial complex I activity and NAD+/NADH balance regulate breast cancer progression. J Clin Invest (2013) 123:1068-81. doi:10.1172/JCI64264

127. He Y, Wu J, Dressman DC, Iacobuzio-Donahue C, Markowitz SD, Velculescu VE, et al. Heteroplasmic mitochondrial DNA mutations in normal and tumour cells. Nature (2010) 464:610-4. doi:10.1038/nature08802

128. Park JS, Sharma LK, Li H, Xiang R, Holstein D, Wu J, et al. A heteroplasmic, not homoplasmic, mitochondrial DNA mutation promotes tumorigenesis via alteration in reactive oxygen species generation and apoptosis. Hum Mol Genet (2009) 18:1578-89. doi:10.1093/hmg/ddp069

129. Chatterjee A, Mambo E, Sidransky D. Mitochondrial DNA mutations in human cancer. Oncogene (2006) 25:4663-74. doi:10.1038/sj.onc.1209604

130. Yokota M, Shitara H, Hashizume O, Ishikawa K, Nakada K, Ishii R, et al. Generation of trans-mitochondrial mito-mice by the introduction of a pathogenic G13997A mtDNA from highly metastatic lung carcinoma cells. FEBS Lett (2010) 584:3943-8. doi:10.1016/j.febslet.2010.07.048

131. Ishikawa $K$, Takenaga $K$, Akimoto $M$, Koshikawa N, Yamaguchi A, Imanishi $H$, et al. ROS-generating mitochondrial DNA mutations can regulate tumor cell metastasis. Science (2008) 320:661-4. doi:10.1126/science.1156906

132. Rimessi A, Bonora M, Marchi S, Patergnani S, Marobbio CMT, Lasorsa FM, et al. Perturbed mitochondrial $\mathrm{Ca} 2+$ signals as causes or consequences of mitophagy induction. Autophagy (2013) 9:1677-86. doi:10.4161/auto.24795

133. Gottlieb RA, Carreira RS. Autophagy in health and disease. 5. Mitophagy as a way of life. Am J Physiol Cell Physiol (2010) 299:C203-10. doi:10.1152/ajpcell. 00097.2010

134. Elmore SP, Qian T, Trost LC, Nishimura Y, Herman B, Lemasters JJ. Detection of mitochondrial depolarization during autophagy by confocal fluorescence resonance energy transfer (CFRET). Cell Vis J Anal Morphol (1997) 4:170-1.

135. Kang MR, Kim MS, Oh JE, Kim YR, Song SY, Kim SS, et al. Frameshift mutations of autophagy-related genes ATG2B, ATG5, ATG9B and ATG12 in gastric and colorectal cancers with microsatellite instability. J Pathol (2009) 217:702-6. doi:10.1002/path.2509
136. Aita VM, Liang XH, Murty VV, Pincus DL, Yu W, Cayanis E, et al. Cloning and genomic organization of beclin 1, a candidate tumor suppressor gene on chromosome 17q21. Genomics (1999) 59:59-65. doi:10.1006/geno.1999.5851

137. Kim MS, Jeong EG, Ahn CH, Kim SS, Lee SH, Yoo NJ. Frameshift mutation of UVRAG, an autophagy-related gene, in gastric carcinomas with microsatellite instability. Hum Pathol (2008) 39:1059-63. doi:10.1016/j.humpath.2007. 11.013

138. Ralph SJ, Rodríguez-Enríquez S, Neuzil J, Saavedra E, Moreno-Sánchez R. The causes of cancer revisited: "mitochondrial malignancy" and ROS-induced oncogenic transformation - why mitochondria are targets for cancer therapy. Mol Aspects Med (2010) 31:145-70. doi:10.1016/j.mam.2010.02.008

139. Galluzzi L, Morselli E, Kepp O, Vitale I, Rigoni A, Vacchelli E, et al. Mitochondrial gateways to cancer. Mol Aspects Med (2010) 31:1-20. doi:10.1016/j.mam. 2009.08.002

140. Chatterjee A, Dasgupta S, Sidransky D. Mitochondrial subversion in cancer. Cancer Prev Res (Phila) (2011) 4:638-54. doi:10.1158/1940-6207.CAPR-100326

141. Grandemange S, Herzig S, Martinou J-C. Mitochondrial dynamics and cancer. Semin Cancer Biol (2009) 19:50-6. doi:10.1016/j.semcancer.2008.12.001

142. O'Brien CA, Pollett A, Gallinger S, Dick JE. A human colon cancer cell capable of initiating tumour growth in immunodeficient mice. Nature (2007) 445:106-10. doi:10.1038/nature05372

143. Al-Hajj M, Wicha MS, Benito-Hernandez A, Morrison SJ, Clarke MF. Prospective identification of tumorigenic breast cancer cells. Proc Natl Acad Sci U S A (2003) 100:3983-8. doi:10.1073/pnas.0530291100

144. Clarke MF, Dick JE, Dirks PB, Eaves CJ, Jamieson CHM, Jones DL, et al. Cancer stem cells - perspectives on current status and future directions: AACR workshop on cancer stem cells. Cancer Res (2006) 66:9339-44. doi:10.1158/00085472.CAN-06-3126

145. Singh SK, Hawkins C, Clarke ID, Squire JA, Bayani J, Hide T, et al. Identification of human brain tumour initiating cells. Nature (2004) 432:396-401. doi:10.1038/nature03128

146. Vega-Naredo I, Loureiro R, Mesquita KA, Barbosa IA, Tavares LC, Branco AF, et al. Mitochondrial metabolism directs stemness and differentiation in P19 embryonal carcinoma stem cells. Cell Death Differ (2014) 21(10):1560-74. doi:10.1038/cdd.2014.66

147. Gogvadze V. Targeting mitochondria in fighting cancer. Curr Pharm Des (2011) 17:4034-46. doi:10.2174/138161211798764933

148. Suh DH, Kim M-K, Kim HS, Chung HH, Song YS. Mitochondrial permeability transition pore as a selective target for anti-cancer therapy. Front Oncol (2013) 3:41. doi:10.3389/fonc.2013.00041

Conflict of Interest Statement: The authors declare that the research was conducted in the absence of any commercial or financial relationships that could be construed as a potential conflict of interest.

Received: 18 July 2014; paper pending published: 04 August 2014; accepted: 14 October 2014; published online: 17 November 2014.

Citation: Bonora $M$ and Pinton P (2014) The mitochondrial permeability transition pore and cancer: molecular mechanisms involved in cell death. Front. Oncol. 4:302. doi: 10.3389/fonc.2014.00302

This article was submitted to Molecular and Cellular Oncology, a section of the journal Frontiers in Oncology.

Copyright (C) 2014 Bonora and Pinton. This is an open-access article distributed under the terms of the Creative Commons Attribution License (CC BY). The use, distribution or reproduction in other forums is permitted, provided the original author (s) or licensor are credited and that the original publication in this journal is cited, in accordance with accepted academic practice. No use, distribution or reproduction is permitted which does not comply with these terms. 